amyloid- $\beta$, which is a

hallmark of Alzheimer's

disease.

The immune cells, called microglia, normally absorb and digest amyloid- $\beta$ after lipoproteins called APOE and CLU attach to it. Lino Gonzalez and Morgan Sheng of drug firm Genentech in South San Francisco, California, and their colleagues looked for interactions between human proteins, and found that a receptor on microglia called TREM2 binds to APOE and CLU. Mouse microglia lacking Trem 2 were less effective at absorbing amyloidlipoprotein complexes, and digested them more slowly than normal cells did. Microglia taken from people carrying a TREM2 mutation were also less able to take up the complexes.

Mutations in the genes that encode TREM2, APOE and CLU have been linked to Alzheimer's, and so the results show how these different genetic risk factors could be linked.

Neuron 91, 328-340 (2016) PALAEOCLIMATE

\section{Analysing ancient air in salt crystals}

Gas trapped in ancient bubbles reveals that Earth's atmosphere was rich in oxygen up to 200 million years earlier than models have predicted, well before animal diversity exploded.

Bubbles in salt crystals called halites (pictured) that formed millions of years ago can provide clues to ancient climates. Nigel Blamey of Brock University

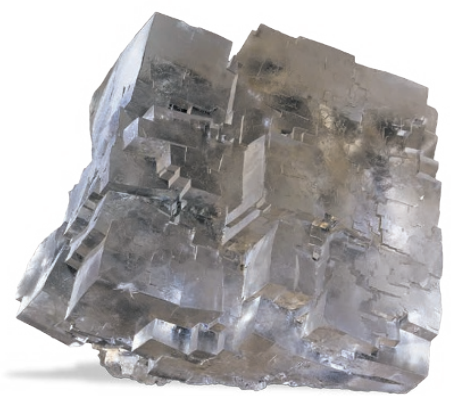

in St Catharines, Ontario, Canada, and his colleagues studied pockets of air inside 815-million-year-old halites from southwest Australia. The air contained nearly $11 \%$ oxygen, more than expected for that time period.

The authors suggest that high oxygen levels drove animal evolution, rather than the other way around. Geology http://doi.org/bmt3 (2016)

\section{OPTICS}

\section{Human eye sees single photons}

People can perceive flashes of light as feeble as a single photon.

Alipasha Vaziri at the Rockefeller University in New York City and his colleagues asked three volunteers to stare into an optical system in the dark and listen to two sounds, one of which was sometimes accompanied by the emission of a photon. During more than 30,000 trials, the participants correctly identified a photon more frequently than would be expected if they had guessed at random.

Going forwards, the team plans to test how the human visual system responds to photons in various quantum states.

Nature Commun. 7, 12172

(2016)

For more on this story, see go.nature.com/2anfrrf

\section{MARINE ECOLOGY}

\section{Ice algae key to Arctic food web}

Even creatures living many metres below the Arctic Ocean's surface rely on algae that grow in sea ice and so, like those living near the surface, may feel the negative effects of shrinking ice.

A team led by Doreen

Kohlbach of the Alfred

Wegener Institute Helmholtz Centre for Polar and Marine Research in Bremerhaven, Germany, collected small

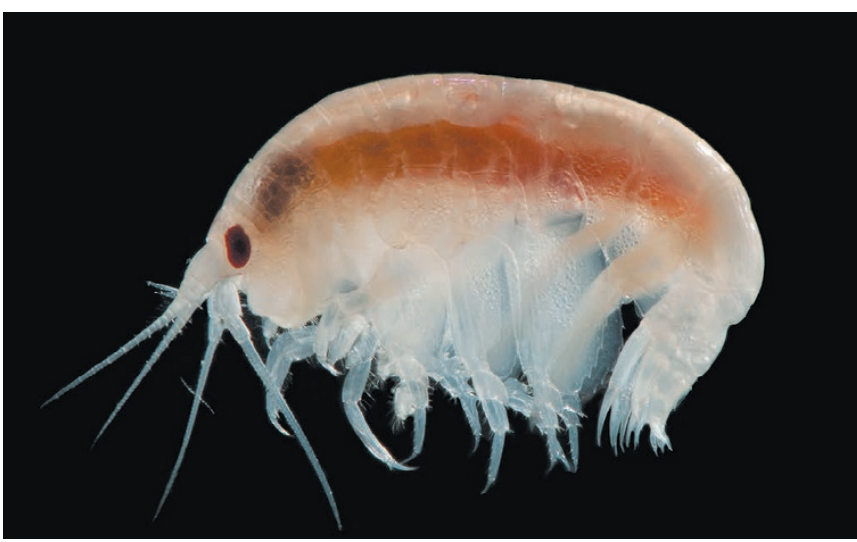

crustaceans and other animals at different depths in the central Arctic Ocean and analysed their fattyacid content to identify the source of carbon in their diets. Organisms living at the water-ice interface (such as Apherusa glacialis; pictured) got as much as $92 \%$ of their carbon from the ice algae. But creatures sampled at up to 50 metres below the surface got $14-55 \%$ of their carbon from the algae.

Melting sea ice means a shrinking habitat for algae, which could lead to decreased nourishment for the entire Arctic food web.

Limnol. Oceanogr. http://doi.org/ bmtq (2016)

\section{NEUROSCIENCE \\ Neurons compete to make memories}

Memories that are formed within a few hours of one another can be encoded by a shared set of neurons.

Sheena Josselyn and Paul Frankland at the Hospital for Sick Children in Toronto, Canada, and their colleagues exposed mice to two fearinducing experiences, each consisting of a different musical tone paired with a mild electric shock to the foot. When the events occurred within 6 hours of each other, the associated memories were encoded by some of the same neurons in the lateral amygdala - a brain area involved in fear memory. However, fear memories separated by 24 hours were encoded by separate groups of neurons.

The researchers found that neurons stimulated by the first experience transiently suppressed the excitability of neighbouring neurons, increasing the chances that the same cells will respond to a second experience that follows soon afterwards.

Science 353, 383-387 (2016)

\section{ENERGY}

\section{Carbon capture makes electricity}

A battery developed from widely available materials produces electricity by capturing carbon dioxide from gas mixtures.

Wajdi Al Sadat and Lynden Archer at Cornell University in Ithaca, New York, designed an aluminiumbased electrochemical cell. At the cell's cathode, oxygen is reduced to form a superoxide, which then binds $\mathrm{CO}_{2}$ and combines with aluminium from the anode to form aluminium oxalate.

The authors estimate that for each kilogram of aluminium, more than 9 kilograms of $\mathrm{CO}_{2}$ can be captured from flue gas and transformed to generate 3.6 kilowatt-hours of electricity. This offers a strategy to reduce $\mathrm{CO}_{2}$ emissions while producing power.

Sci. Adv. 2, e1600968 (2016)

\section{DNATURE.COM}

For the latest research published by Naturevisit:

www.nature.com/latestresearch 